is an underrecognized adverse effect that can potentially cause significant morbidity and mortality.

Objectives: To study incidence, presentation, and characteristics of $\mathrm{HCQ}$-induced AVB in IMID.

Methods: Open-label single center study of 293 patients with IMID treated with $\mathrm{HCQ}$ for at least 3 months. Electrocardiograms were analyzed at baseline and during $\mathrm{HCQ}$ treatment. In addition, a comparative study between patients with and without $A V B$ was conducted.

Results: We studied 293 patients (270 women/ 23 men; mean age 59.7 \pm 14.7 years). Underlying IMID were Systemic Lupus Erythematosus (SLE) ( $n=109$, $40.6 \%$ ); undifferentiated connective-tissue disease ( $n=70,23.9 \%)$, Sjögren's syndrome (SS) $(n=70,23.9 \%)$, antiphospholipid syndrome $(n=31,10.6 \%)$ and other IMID $(n=13,4.4 \%)$. HCQ was used for $4.1 \pm 3.5$ years.

After $11.8 \pm 8.9$ years of follow-up (HCQ mean cumulative dose: $979.7 \pm 272.1 \mathrm{~g}$ ). AVB was observed in 19 out of $293(6.5 \%)$ patients: 16 (84.2\%) were first-degree AVB and $3(15.8 \%)$ complete AVB. 4 (21.2\%) patients with AVB were treated with a permanent pacemaker.

Presentation of atrioventricular block according to hydroxychloroquine incidence rate and treatment duration is shown in Figure 1. Most of AVB happened in the first 40 months, regardless of HCQ cumulative dose.

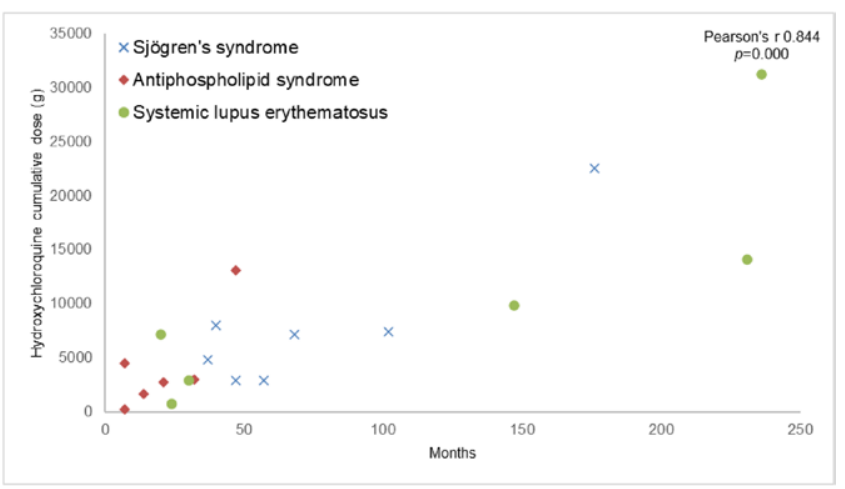

Figure 1. Presentation of atrioventricular block according to hydroxychloroquine incidence rate and treatment duration.

A comparative study between patients with and without AVB was performed (Table 1). Patients with AVB were older $(p=0.014)$ and had a higher incidence of diabetes mellitus ( $p=0.033$ ). HCQ cumulative dose and duration of IMID were similar in both groups $(p>0.05)$.

Other HCQ adverse effects were retinopathy $(n=16,5.4 \%)$, gastrointestinal alterations $(n=14,4.8 \%)$, cutaneous alterations $(n=14,4.8 \%)$, allergic reactions $(n=4$, $1.4 \%)$ and myopathy $(n=1,0.3 \%)$.

Conclusion: AVB was observed in $6.5 \%$ of patients with IMID treated with $\mathrm{HCQ}$. Most AVB were first-degree AVB. HCQ increased the risk of developing an AVB in patients with IMID regardless of HCQ cumulative dose or underlying disease duration. Older patients with diabetes mellitus had a higher risk of developing an AVB.

Table 1. Comparative study between patients with and without AVB.

\begin{tabular}{lccc}
\hline & with AVB & without AVB & \\
& & & \\
& $\mathrm{n}=19$ & $\mathrm{n}=274$ & $p$ \\
\hline General features at HCQ onset & & & \\
Age, years mean $\pm \mathrm{SD}$ & $57.4 \pm 14.5$ & $46.4 \pm 16.8$ & $\mathbf{0 . 0 1 4}$ \\
Female, $\mathrm{n}(\%)$ & $17(89.5)$ & $239(87.4)$ & 0.877 \\
Hypertension, $\mathrm{n}(\%)$ & $14(73.7)$ & $149(54.4)$ & 0.118 \\
Dyslipemia, $\mathrm{n}(\%)$ & $11(58.9)$ & $117(42.7)$ & 0.265 \\
Diabetes Mellitus, $\mathrm{n}(\%)$ & $5(26.3)$ & $24(8.7)$ & 0.033 \\
Renal impairment, $\mathrm{n}(\%)$ & $5(26.3)$ & $29(10.7)$ & 0.073 \\
Ischemic cardiopathy, $\mathrm{n}(\%)$ & $2(10.5)$ & $11(3.9)$ & 0.228 \\
CRP, mg/dL median [IQR] & $0.3[0.1-0.5]$ & $0.4[0.3-0.8]$ & 0.343 \\
ESR, mm/h median [IQR] & $17.0[15.0-22.3]$ & $13.0[7.0-29.5]$ & 0.206 \\
Data at last visit (11.8 \pm 8.9 years of follow-up) & & & \\
IMID duration, years mean \pm SD & $11.8 \pm 8.9$ & $14.3 \pm 10.3$ & 0.288 \\
\# Use of other cardiotoxic drugs, $\mathrm{n}(\%)$ & $2(10.5)$ & $11(4.0)$ & 0.723 \\
HCQ cumulative dose, $\mathrm{g}$ mean \pm SD & $813.2 \pm 206.0$ & $996.3 \pm 266.9$ & 0.527 \\
& & & \\
\hline
\end{tabular}

\# (beta blockers, calcium channel blockers, tricyclic drugs, other AVB inducers)
Disclosure of Interests: Alba Herrero-Morant: None declared, Adrián Margarida-de Castro: None declared, Raquel Pérez-Barquín: None declared, Jon Zubiaur-Zamacola: None declared, Miguel Á. González-Gay Speakers bureau: AbbVie, Pfizer, Roche, Sanofi, Lilly, Celgene and MSD, Grant/research support from: AbbVie, MSD, Jansen and Roche, Ricardo Blanco Speakers bureau: AbbVie, Pfizer, Roche, Bristol-Myers, Janssen, Sanofi, Lilly and MSD, Grant/research support from: AbbVie, MSD, and Roche

DOI: 10.1136/annrheumdis-2021-eular.3295

\section{POS1371 BIOLOGICAL THERAPY IN REFRACTORY NEUROBEHÇET'S DISEASE. MULTICENTER STUDY OF 42 PATIENTS}

A. Herrero-Morant ${ }^{1}$, J. L. Martín-Varillas ${ }^{2}$, S. Castañeda ${ }^{3}$, I. GonzálezMazón $^{1}$, O. Maiz ${ }^{4}$, A. Blanco ${ }^{4}$, J. Sánchez ${ }^{5}$, N. Ortego ${ }^{6}$, E. Raya ${ }^{6}$, A. Olive ${ }^{7}$, A. Brandy-Garcia ${ }^{7}$, Á. Prior-Español ${ }^{7}$, C. Moriano ${ }^{8}$, E. Diez Alvarez $^{8}$, R. Melero ${ }^{9}$, J. Graña ${ }^{10}$, Á. Seijas-López ${ }^{10}$, A. UrruticoecheaArana $^{11}$, A. Ramos Calvo ${ }^{12}$, C. Delgado Beltrán ${ }^{13}$, M. Loredo Martínez ${ }^{13}$, E. Salgado-Pérez ${ }^{14}$, F. Sivera ${ }^{15}$, I. Torre-Salaberri ${ }^{16}$, J. Narváez ${ }^{17}$, J. L. Andréu Sánchez ${ }^{18}$, O. Martínez González ${ }^{19}$, R. Gómez de la Torre ${ }^{20}$, S. Fernández ${ }^{21}$, S. Romero-Yuste ${ }^{22}$, G. Espinosa ${ }^{23}$, M. Á. González-Gay ${ }^{1}$, R. Blanco'. ' Hospital Universitario Marqués de Valdecilla, Rheumatology, Santander, Spain; ${ }^{2}$ Hospital de Sierrallana, Rheumatology, Torrelavega, Spain; ${ }^{3}$ Hospital Universitario La Princesa, Rheumatology, Madrid, Spain; ${ }^{4}$ Hospital Universitario de Donostia, Rheumatology and Ophtalmology, San Sebastián, Spain; ${ }^{5}$ Hospital 12 de octubre, Rheumatology, Madrid, Spain; ${ }^{6}$ Hospital San Cecilio, Rheumatology and Internal Medicine, Granada, Spain; ${ }^{7}$ Hospital Universitario Germans Trias i Pujol, Rheumatology, Barcelona, Spain; ${ }^{8}$ Hospital de León, Rheumatology, León, Spain; ${ }^{9}$ Complejo Hospitalario de Vigo, Rheumatology, Vigo, Spain; ${ }^{10} \mathrm{Hospital}$ Universitario de A Coruña, Rheumatology, A Coruña, Spain; ${ }^{11}$ Hospital Can Misses, Rheumatology, Ibiza, Spain; ${ }^{12}$ Complejo Hospitalario de Soria, Rheumatology, Soria, Spain; ${ }^{13}$ Hospital Clínico Lozano Blesa, Rheumatology, Zaragoza, Spain; ${ }^{14}$ Complejo Hospitalario Universitario de Ourense, Rheumatology, Ourense, Spain; ${ }^{15}$ Hospital General Universitario de Elda, Rheumatology, Elda, Spain; ${ }^{16}$ Hospital de Basurto, Rheumatology, Bilbao, Spain; ${ }^{17}$ Hospital Bellvitge, Rheumatology, Barcelona, Spain; ${ }^{18} \mathrm{Hospital}$ Universitario Puerta de Hierro, Rheumatology, Madrid, Spain; ${ }^{19} \mathrm{Hospital}$ Clínico Universitario de Salamanca, Rheumatology, Salamanca, Spain; ${ }^{20}$ Hospital Universitario Central de Asturias, Internal Medicine, Oviedo, Spain; ${ }^{21}$ Hospital Universitario de Cabueñes, Rheumatology, Gijón, Spain; ${ }^{22}$ Complejo Hospitalario Universitario de Pontevedra, Rheumatology, Pontevedra, Spain; ${ }^{23}$ Hospital Clínic de Barcelona, Internal Medicine, Barcelona, Spain

Background: Neuro-Behçet's disease (NBD) is a severe complication of Behcet's disease (BD). Despite well-established therapies with glucocorticoids and conventional immunosuppressants (cIS), a significant proportion of patients are refractory.

Objectives: To assess efficacy and safety of biologic therapy (BT) in NBD refractory to glucocorticoids and at least one cIS.

Methods: Open-label multicenter study of refractory NBD from 23 different referral Spanish Hospitals. Main outcome was neurological response. Secondarily, analytical efficacy was measured by Erythrocyte Sedimentation Rate (ESR), C-Reactive Protein (CRP) and Hemoglobin $(\mathrm{Hb})$ at baseline, 6 months, 1 year and 2 years.

Results: We studied 42 patients (21 women/ 21 men; mean age 40.4 410.8 years). HLA B51 was positive in 15 out of $37(40.5 \%)$ patients tested. Non-neurological manifestations were oral ulcers $(n=41,97.6 \%)$, genital ulcers $(n=31,73.8 \%)$, skin lesions $(n=28,66.7 \%)$, arthralgia $(n=27,64.3 \%)$, uveitis $(n=21,50.0 \%)$, arthritis $(n=9,21.4 \%)$, venous thrombosis $(n=9$, $21.4 \%)$ and arterial thrombosis $(n=4,9.5 \%)$. The underlying neurologic manifestation were parenchymal $(n=34,81.0 \%)$ and non-parenchymal $(n=17$, $40.5 \%)$ involvement (Table 1). The first BT used was infliximab $(n=20)$, adalimumab $(n=13)$, golimumab $(n=3)$, tocilizumab $(n=3)$ and etanercept $(n=2)$.

After $58.2 \pm 51.4$ months since initiation of BT, neurological response was complete $(n=27 ; 64.3 \%)$, or partial $(n=11,26.1 \%)$ (Figure 1$)$. Only $4(9.5 \%)$ patients did not respond. After 6 months of BT, ESR improved from. $31.5 \pm 25.6$ to $15.3 \pm 11.9 \mathrm{~mm} / \mathrm{h}$ $(\mathrm{p}=0.005)$, CRP from $1.4[0.2-12.8]$ to $0.3[0.1-3] \mathrm{mg} / \mathrm{dL}(\mathrm{p}=0.002)$ and $\mathrm{Hb}$ from $13.1 \pm 1.6$ to $13.8 \pm 1.3 \mathrm{~g} / \mathrm{dL}(\mathrm{p}=0.005)$ 
Table 1. Neurologic manifestation of $\mathbf{4 2}$ patients with refractory neurobehçet's disease treated with biologic therapy.

\begin{tabular}{ll}
\hline Parenchymal subtype, $\boldsymbol{n}(\%)$ & $\mathbf{3 4}(\mathbf{8 1 . 0 )}$ \\
-Hemiparesis & $8(19.1)$ \\
-Polineuropathy & $8(19.1)$ \\
-Encephalopathy & $6(14.3)$ \\
-Cognitive impairments & $4(9.5)$ \\
-Optic neuropathy & $4(9.5)$ \\
-Ophtalmoparesis & $4(9.5)$ \\
-Other cranial nerve involvement & $3(7.1)$ \\
-Hemihypoesthesia & $3(7.1)$ \\
-Cerebellar dysphasia & $1(2.4)$ \\
-Cerebellar involvement & $1(2.4)$ \\
-Non-steroidal psicosis & $1(2.4)$ \\
Non-parenchymal subtype, $\boldsymbol{n}(\%)$ & $17(40.5)$ \\
-Aseptic meningitis & $12(28.6)$ \\
-Thrombosis & $4(9.5)$ \\
-Intracranial hypertension & $1(2.4)$ \\
\hline
\end{tabular}

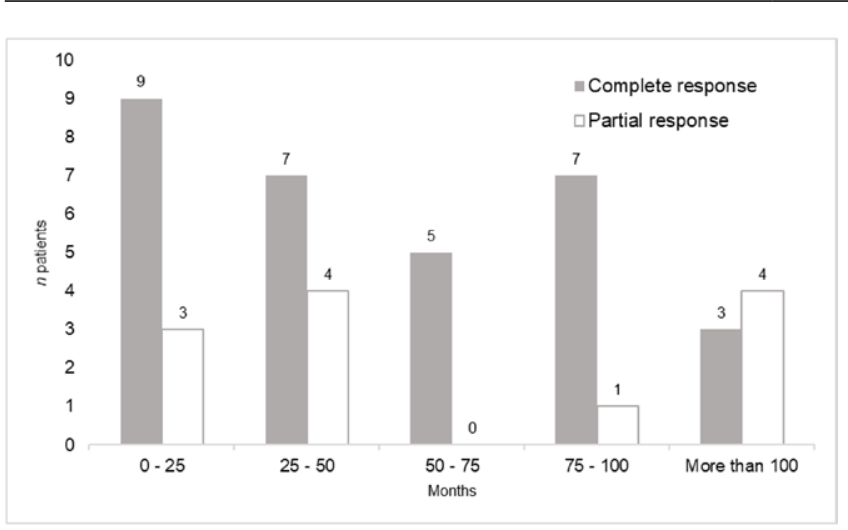

Figure 1. Neurological clinical response to biological therapy.

Primary failure was observed in $16(38.1 \%)$ patients due to inefficacy $(n=11$, $68.8 \%)$ or adverse effects $(n=5,31.3 \%)$. Similarly, causes of secondary failure $(n=6,14.3 \%)$ were inefficacy $(n=5,83.3 \%)$ and adverse effects $(n=1,16.7 \%)$. No serious adverse effects were observed.

Conclusion: BT, especially monoclonal anti-TNF drugs, seems to be effective and safe in refractory NBD.

Disclosure of Interests: Alba Herrero-Morant: None declared, José Luis Martín-Varillas Grant/research support from: AbbVie, Pfizer, Lilly, Janssen, and Celgene, Santos Castañeda: None declared, Iñigo González-Mazón: None declared, Olga Maiz: None declared, Ana Blanco Speakers bureau: AbbVie, Julio Sánchez: None declared, Norberto Ortego: None declared, Enrique Raya Speakers bureau: MSD, Grant/research support from: AbbVie, Alejandro Olive: None declared, Anahy Brandy-Garcia: None declared, Águeda PriorEspañol: None declared, Clara Moriano: None declared, Elvira Diez Alvarez: None declared, Rafael Melero: None declared, Jenaro Graña: None declared, Álvaro Seijas-López: None declared, ANA URRUTICOECHEA-ARANA: None declared, Angel Ramos Calvo: None declared, Concepción Delgado Beltrán: None declared, Marta Loredo Martínez: None declared, Eva Salgado-Pérez: None declared, Francisca Sivera: None declared, Ignacio Torre-Salaberri: None declared, J. Narváez Speakers bureau: Bristol-Myers Squibb, José Luis Andréu Sánchez: None declared, Olga Martínez González: None declared, Ricardo Gómez de la Torre: None declared, Sabela Fernández: None declared, Susana Romero-Yuste: None declared, Gerard Espinosa: None declared, Miguel Á. González-Gay Speakers bureau: AbbVie, Pfizer, Roche, Sanofi, Lilly, Celgene and MSD, Grant/research support from: AbbVie, MSD, Jansen and Roche, Ricardo Blanco Speakers bureau: AbbVie, Pfizer, Roche, Bristol-Myers, Janssen, Sanofi, Lilly and MSD, Grant/research support from: AbbVie, MSD, and Roche

DOI: 10.1136/annrheumdis-2021-eular.3407

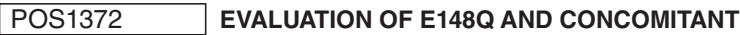 AA AMYLOIDOSIS SECONDARY TO FAMILIAL MEDITERRANEAN FEVER AFTER ADJUSTED CLINICAL-DEMOGRAPHIC CHARACTERISTICS}

Z. S. Arici ${ }^{1}$, M. Romano ${ }^{2}$, D. Piskin ${ }^{3}$, F. Guzel ${ }^{4}$, M. Yilmaz ${ }^{5}$, E. Demirkaya ${ }^{2}$. ${ }^{1}$ Sanliurfa Training and Research Hospital, Paediatric Rheumatology, Sanliurfa, Turkey; ${ }^{2}$ Schulich School of Medicine \& Dentistry, University of Western Ontario, Paediatric Rheumatology, London, Canada; ${ }^{3}$ Lawson Health Research Institute,
Pediatrics, London, Canada; ${ }^{4}$ Gentera Biotechnology, Biotechnology, Istanbul, Turkey; ${ }^{5}$ Epigenetic Health Solutions, Unit of Nephrology, Ankara, Turkey

Background: Amyloid A (AA) amyloidosis, previously known as secondary or reactive amyloidosis, is a long-recognized severe complication of some chronic inflammatory diseases. The pathogenesis and risk factors for amyloidosis in Familial Mediterranean Fever (FMF) remain partially understood (1). The development of AA amyloidosis is dependent on ethnicity and country of residence (2). In the pre-colchicine era, renal AA-amyloidosis was largely reported patients of Turkish $(67 \%)$ and Sephardic Jewish ancestry $(26.5 \%)(2,3)$. Currently it's well known that the MEFV M694V variant associated with high risk of amyloidosis however, mutations on exon 2, specifically $\mathrm{E} 148 \mathrm{Q}$ variant remained controversial. Objectives: To evaluate the E148Q mutation variant and concomitant AA Amyloidosis secondary to FMF after adjusted clinical-demographic characteristics. Methods: Patients were recruited from the renal unit at Epigenetic Health Center outpatient clinic in Turkey between September 2003 and February 2020. Patients who had biopsy confirmed FMF related $A A$ amyloidosis were included the study. Tel-Hashomer criteria were applied in the diagnosis of FMF. The clinical characteristics of FMF patients and medication history were recorded by the physician at the time of registry entry. All patients had detailed baseline assessment of clinical features, renal functions, genetic testing, histopathological diagnosis of amyloidosis, and treatment received. We performed multiple comparisons according to the age of diagnosis, demographic features, disease phenotype, allele frequency, type of mutation and mortality. Statistical analysis was performed with Statistical Package of Social Science (SPSS) for Windows, version 15.0 (SPSS Inc, Chicago, IL).

Results: Our registry consists of 195 patients with a diagnosis of AA amyloidosis. Complete information on 169 patients (lost to follow up, $n=26$ ) were included. The median age was 36 (19-49) years; male/female ratio was $1.6(104 / 65)$. The median follow-up duration was 15.0 years (4-17 years). There were 101 patients diagnosed with FMF $<18$ years of age and 68 patients diagnosed $\geq 18$ years of age. All participants developed renal amyloidosis before the age of 32 years. Family history of FMF was documented in 56 patients $(33.1 \%)$ and family history of amyloidosis was present in 41 patients $(24.3 \%)$. The three most common clinical symptoms were fever (84,6\%), abdominal pain (71.6\%) and arthritis $(66.9 \%)$. During the follow-up, 5 patients started dialysis treatment and 9 patients had kidney transplantation. The most common allele frequency across patients was M694V (60.6\%), E148Q (21.4\%) and M680I (10.3\%). The most frequent mutations were M694V/M694V (63.3\%), M694V/E148Q (20.8\%) and E148Q/E148Q (15.8\%). During the follow up period, 15 patients (10 male, 5 female) died. In those that died, the mutations in 14 had M694V/M694Vand one demonstrated E148Q/E148Q.

Conclusion: Patients with FMF related AA amyloidosis have an increased risk for mortality. This study confirmed the association between M694V and FMF-associated AA amyloidosis, which has been reported in many studies. Close clinical follow-up and further evaluation of patients with the E148Q mutation is warranted specifically if residing in FMF endemic areas. The possible relationship between $\mathrm{E} 148 \mathrm{Q}$ and $\mathrm{AA}$ amyloidosis need to be confirmed in other cohorts.

REFERENCES:

[1] Erer B, Demirkaya E, Ozen S, Kallinich T. What is the best acute phase reactant for familial Mediterranean fever follow-up and its role in the prediction of complications? A systematic review. Rheumatology international. 2016;36(4):483-7.

[2] Touitou I, Sarkisian T, Medlej-Hashim M, Tunca M, Livneh A, Cattan D, et al. Country as the primary risk factor for renal amyloidosis in familial Mediterranean fever. Arthritis and rheumatism. 2007;56(5):1706-12.

[3] Pras M, Bronshpigel N, Zemer D, Gafni J. Variable incidence of amyloidosis in familial Mediterranean fever among different ethnic groups. Johns Hopkins Med J. 1982;150(1):22-6.

Disclosure of Interests: None declared

DOI: 10.1136/annrheumdis-2021-eular.3420

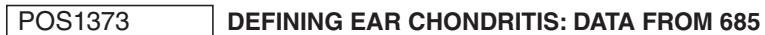 PATIENTS WITH RELAPSING POLYCHONDRITIS}

M. Ferrada ${ }^{1}$, N. Costedoat-Chalumeau ${ }^{2}$, G. Moulis ${ }^{3}$, N. Linn ${ }^{4}$, E. Rose ${ }^{1}$, P. Grayson $1 .{ }^{1} \mathrm{NIH}, \mathrm{NIAMS}$, Bethesda, United States of America; ${ }^{2}$ APHP, Université de Paris, Paris, France; ${ }^{3}$ Toulouse University Hospital, Department of Internal Medicine, Toulouse, France; ${ }^{4}$ Relapsing Polychondritis Foundation, Relapsing Polychondritis Foundation, New York, United States of America

Background: Ear chondritis is often considered the pathognomonic feature of relapsing polychondritis (RP). Although painful redness and swelling of the pinna and a resultant cauliflower ear are universally recognized as chondritis, the complete spectrum of symptoms associated with ear chondritis have not been well described. 